\title{
New Approach to the Synthesis of Planar Binuclear Phthalocyanines of Mg, Zn and Rare Earth Elements
}

\author{
Alexander Yu. Tolbin, ${ }^{\mathrm{a}, \mathrm{b}}$ Victor E. Pushkarev, ${ }^{\mathrm{b}}$ Larisa G. Tomilova, ${ }^{\mathrm{a}, \mathrm{b}}$ \\ and Nicolay S. Zefirov ${ }^{\mathrm{a}}$ \\ ${ }^{a}$ M.V. Lomonosov Moscow State University, Moscow, 119991, Russia \\ ' Institute of Physiologically Active Compounds, Russian Academy of Sciences, Chernogolovka, Moscow Region, 142432, Russia \\ ${ }^{\circledR}$ Corresponding authorE-mail: tom@org.chem.msu.ru
}

\begin{abstract}
Direct synthesis of planar binuclear phthalocyanine metallocomplexes sharing common annulated benzene ring providing the yields of target products up to 40\%, in comparison with earlier described 5-11\% yields, was developed. Generality of the elaborated method was shown by the example of synthesis of divalent (Mg, Zn) and rare-earth (Lu, $\mathrm{Yb}, \mathrm{Dy})$ metal complexes.
\end{abstract}

Keywords: Phthalocyanine, binuclear complex, planar-type, building blocks, rare earth metal complexes.

\section{Introduction}

Interest to binuclear phthalocyanines grows out of their unusual physique-chemical properties due to the structural features and the specific behavior in solutions. Extension of the $\pi$-system in this type of complexes provides effective electronic conjugation between macrocycles and consequently leads to the unique spectral properties. ${ }^{[1,2]}$ Such compounds have the intensive absorption in the near IR region. ${ }^{[3,4]}$ Thus, elaboration of the convenient and available approaches to this type of complexes is extremely actual.

\section{Experimental}

${ }^{1} \mathrm{H}$ NMR spectra were recorded on Bruker AM-300 (300.13 $\mathrm{MHz}$ ). UV-vis spectra were recorded on ThermoSpectronic Helios- $\alpha$ in quartz cells of $0.5 \mathrm{~cm}$ thickness in THF. Mass-spectra were registered on Autoflex II (MALDI-TOF, matrix - 2,5-dihydroxybenzoic acid - DHB) equipment. Column chromatography was carried out on BioBeads SX-1 («BioRad»). All solvents were purified using standard procedures directly before their use. Salts $\mathrm{Mg}(\mathrm{OAc})_{2} \cdot \mathrm{H}_{2} \mathrm{O}, \mathrm{Zn}(\mathrm{OAc})_{2} \cdot 2 \mathrm{H}_{2} \mathrm{O}, \mathrm{Lu}(\mathrm{OAc})_{3} \cdot 3 \mathrm{H}_{2} \mathrm{O}, \mathrm{Yb}(\mathrm{OAc})_{3} \cdot 4 \mathrm{H}_{2} \mathrm{O}$, $\mathrm{Dy}(\mathrm{OAc})_{3} \cdot 4 \mathrm{H}_{2} \mathrm{O}$ were held in a vacuum desiccator for $4 \mathrm{~h}$ at $100^{\circ} \mathrm{C}$. Compounds $\mathbf{1},{ }^{[5]} \mathbf{2} \mathbf{a}, \mathbf{b}^{[6,7]}$ were prepared according to described procedures.

General procedure for planar complexes, 3a-g. To the solution of $\mathbf{1}(0.48 \mathrm{mmol})$ and $\mathbf{2 a}$ or $\mathbf{2 b}(4.72 \mathrm{mmol})$ in isoamyl alcohol (30 ml) $\mathrm{CH}_{3} \mathrm{OLi}(11.79 \mathrm{mmol})$ was added. The mixture was refluxed for $2 \mathrm{~h}$, then corresponding acetate salt $(2.83 \mathrm{mmol})$ was added and refluxing was continued for $30 \mathrm{~min}$. After the reaction being completed the mixture was cooled, the solvent was evaporated at reduced pressure. The solid residue was washed with aqueous (1:1) methanol $(2 \times 50 \mathrm{ml})$ for removal of non-phthalocyanine impurities and then separated on BioBeads SX-1 (THF) to give complexes 3a-g.

${ }^{1} \mathrm{H}$ NMR spectroscopic data for 3a. $\delta_{\mathrm{H}}\left(300 \mathrm{MHz}, \mathrm{THF}-\mathrm{d}_{8}\right.$, $\left.25^{\circ} \mathrm{C}\right) \mathrm{ppm}: 1.25\left(\mathrm{~s}, 36 \mathrm{H}, \mathrm{CH}_{2} \mathrm{CH}_{2} \mathrm{CH}_{2} \mathrm{CH}_{3}\right), 1.55-1.75(\mathrm{~m}, 24 \mathrm{H}$, $\left.\mathrm{CH}_{2} \mathrm{CH}_{2} \mathrm{CH}_{2} \mathrm{CH}_{3}\right), 1.85-2.00\left(\mathrm{~m}, 24 \mathrm{H}, \mathrm{CH}_{2} \mathrm{CH}_{2} \mathrm{CH}_{2} \mathrm{CH}_{3}\right), 3.25-$ $4.00\left(\mathrm{~m}, 24 \mathrm{H}, \mathrm{CH}_{2} \mathrm{CH}_{2} \mathrm{CH}_{2} \mathrm{CH}_{3}\right), 8.20(\mathrm{~s}, 4 \mathrm{H}, \mathrm{Ar}), 9.38(\mathrm{~s}, 8 \mathrm{H}$, Ar), 11.45 (s, 2 H, Ar).
${ }^{1} H$ NMR spectroscopic data for $\mathbf{3 b} . \delta_{\mathrm{H}}\left(300 \mathrm{MHz}, \mathrm{THF}-\mathrm{d}_{8}\right.$, $\left.25^{\circ} \mathrm{C}\right)$ ppm: $1.20\left(\mathrm{~m}, 36 \mathrm{H}, \mathrm{CH}_{2} \mathrm{CH}_{2} \mathrm{CH}_{2} \mathrm{CH}_{3}\right), 1.64-1.76(\mathrm{~m}, 24 \mathrm{H}$, $\mathrm{CH}_{2} \mathrm{CH}_{2} \mathrm{CH}_{2} \mathrm{CH}_{3}$ ), 1.81-2.00 (m, 24H, $\mathrm{CH}_{2} \mathrm{CH}_{2} \mathrm{CH}_{2} \mathrm{CH}_{3}$ ), 3.20-4.09 $\left(\mathrm{m}, 24 \mathrm{H}, \mathrm{CH}_{2} \mathrm{CH}_{2} \mathrm{CH}_{2} \mathrm{CH}_{3}\right), 8.25$ (s, 4H, Ar), 9.34 (s, 8H, Ar), 11.50 (s, 2H, Ar).

${ }^{1} H$ NMR spectroscopic data for $3 \mathbf{c} . \delta_{\mathrm{H}}\left(300 \mathrm{MHz}, \mathrm{THF}-\mathrm{d}_{8}\right.$, $\left.25^{\circ} \mathrm{C}\right) \mathrm{ppm}: \quad 1.71\left(\mathrm{~s}, 54 \mathrm{H}, \mathrm{CH}_{3}\right), 8.15-9.34(\mathrm{~s}, 18 \mathrm{H}, \mathrm{Ar}), 11.35(\mathrm{~s}$, $2 \mathrm{H}, \mathrm{Ar}$ ).

${ }^{1} H$ NMR spectroscopic data for $\mathbf{3 d}$. $\delta_{\mathrm{H}}\left(300 \mathrm{MHz}, \mathrm{THF}-\mathrm{d}_{8}\right.$, $\left.25^{\circ} \mathrm{C}\right) \mathrm{ppm}: 1.79\left(\mathrm{~s}, 54 \mathrm{H}, \mathrm{CH}_{3}\right), 8.22-9.40(\mathrm{~s}, 18 \mathrm{H}, \mathrm{Ar}), 11.20(\mathrm{~s}$, $2 \mathrm{H}, \mathrm{Ar})$.

${ }^{1} H$ NMR spectroscopic data for 3e. $\delta_{\mathrm{H}}\left(300 \mathrm{MHz}, \mathrm{THF}-\mathrm{d}_{8}\right.$, $\left.25{ }^{\circ} \mathrm{C}\right) \mathrm{ppm}: 1.75\left(\mathrm{~s}, 54 \mathrm{H}, \mathrm{CH}_{3}\right), 6.45-7.20(\mathrm{~m}, 18 \mathrm{H}, \mathrm{Ar}), 9.45(\mathrm{~m}$, $2 \mathrm{H}, \mathrm{Ar})$.

\section{Results and Discussion}

Classic approach to the synthesis of planar binuclear phthalocyanines is based on the mixed cyclization of initial phthalogens - phthalodinitriles or 1,3-diiminoisoindolines. This method even being modified in some way ${ }^{[4]}$ leads to the target complexes in only 5-11\% yields. Moreover, in the case of rare-earth elements (REE) we have found the classical method to be unsuccessful in obtaining of the target complexes even in the trace amounts. Main disadvantage of this approach, from our point of view, is a preferential progress of the side olygomerization reactions, resulting in phthalocyanine polymers ${ }^{[8]}$ as the main products.

Earlier we have demonstrated the stage-by-stage macrocycle formation on the example of clamshell-type binuclear phthalocyanine synthesis. ${ }^{[9]}$ It can be supposed that in present investigation the cyclization also proceeds consecutively, and the rate of second phthalocyanine ring formation is likely to compete with uncontrolled interaction of several unsymmetrically substituted monophthalocyanine molecules (with $o$-CN-groups or 1,3-diiminoisoindoline fragment) and phthalogens. Extent of this side process is supposed to be dependent on the nature of the central metal ion. Such argumentation has formed a basis for the develop- 
<smiles>N=c1[nH]c(=N)c2cc3c(=N)[nH]c(=N)c3cc12</smiles>

1

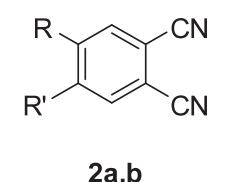

$\mathrm{a}: \mathrm{R}=\mathrm{R}^{\prime}={ }^{\mathrm{n}} \mathrm{Bu}$

b: $R={ }^{t} B u(H), R^{\prime}=H\left({ }^{t} B u\right)$

\section{1. $\mathrm{CH}_{3} \mathrm{OLi} /{ }^{\mathrm{i}} \mathrm{AmOH}$}

2. $\mathrm{M}(\mathrm{OAc})_{n} \cdot \mathrm{mH}_{2} \mathrm{O}$

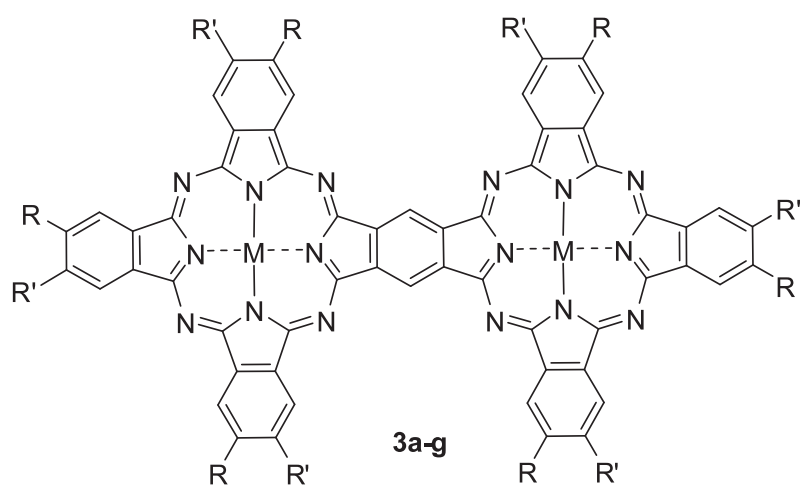

$$
\begin{aligned}
& \text { a: } R=R^{\prime}={ }^{n} B u ; M=M g \\
& \text { b: } \mathrm{R}=\mathrm{R}^{\prime}={ }^{\mathrm{n}} \mathrm{Bu} ; \mathrm{M}=\mathrm{Zn} \\
& \mathrm{d}: \mathrm{R}={ }^{\mathrm{t}} \mathrm{Bu}(\mathrm{H}) ; \mathrm{R}^{\prime}=\mathrm{H}\left({ }^{\mathrm{t}} \mathrm{Bu}\right) ; \mathrm{M}=\mathrm{Zn} \\
& \text { c: } R={ }^{\mathrm{t}} \mathrm{Bu}(\mathrm{H}) ; \mathrm{R}^{\prime}=\mathrm{H}\left({ }^{\mathrm{t}} \mathrm{Bu}\right) ; \mathrm{M}=\mathrm{Mg} \\
& \text { e: } R={ }^{\mathrm{t}} \mathrm{Bu}(\mathrm{H}) ; \mathrm{R}^{\prime}=\mathrm{H}\left({ }^{\mathrm{t}} \mathrm{Bu}\right) ; \mathrm{M}=\mathrm{LuOAc} \\
& f: R={ }^{t} B u(H) ; R^{\prime}=H\left({ }^{t} B u\right) ; M=Y b O A c \\
& g: R={ }^{t} B u(H) ; R^{\prime}=H\left({ }^{t} B u\right) ; M=\text { DyOAc }
\end{aligned}
$$

Scheme 1. Synthesis of planar binuclear phthalocyanines 3a-g.

ment of direct synthetic method to planar binuclear phthalocyanines with common annulated benzene ring (Scheme 1).

Improvement of the macrocycle assembling efficiency was achieved using $\mathrm{CH}_{3} \mathrm{OLi}$ as a base. Lithium cations have the least ionic radius among metals and effectively participate in the macrocycle construction forming ionic bonds with isoindolic nitrogen. Methoxide-anions as a hard nucleophilic agent attack the carbon atom of nitrile group more effectively than analogous ion generated from high-boiling alcohols upon addition of the catalytic amount of organic bases, for instance, DBU (1,8-diazabicyclo[5.4.0]undec7 ene) or during autoprotolysis ( $N, N$-dimethylaminoethanol). Using the excess of $\mathrm{CH}_{3} \mathrm{OLi}$ provides a high concentration of methoxide-anions. So it is reasonable to assume that the rate of the nucleophilic attack increases in comparison with classic method, which implies nucleophile generation in catalytic amounts. ${ }^{[5]}$

Taking these facts into account, initially we carried out a mixed cyclization of phthalogens $\mathbf{1}$ and $\mathbf{2} \mathbf{a}, \mathbf{b}$ in the presence of lithium methoxide. The reaction was monitored by UV-vis spectroscopy. The gradual increasing of the main absorption bands intensity - 665 and $820 \mathrm{~nm}$ (THF) was observed eventually. It was found that the amount of the base is the most essential factor affecting the reaction conversion. Maximum efficiency of the annulated lithium complexes formation was achieved via considerable increasing of $\mathrm{CH}_{3} \mathrm{OLi}$ amount (more 20 equiv. in ratio to $\mathbf{1}$ ). Following addition of $\mathrm{Mg}$ and $\mathrm{Zn}$ salts to the reaction mixtures without preliminary isolation of the lithium complexes resulted in the formation of compounds 3a-d. After a few minutes of refluxing target complexes were obtained revealing significant bathochromic shift (14-28 nm) of earlier observed characteristic bands in their UV-vis spectra.

Isolation of the target phthalocyanine products was performed by gel-permeation chromatography on BioBeads SX-1, using THF as eluent. The yields of the compounds 3a-d surprisingly reached $36-40 \%$. After obtaining the binuclear phthalocyanine complexes of bivalent metals in such high yields we attempted to apply the elaborated procedure for the synthesis of analogous REE complexes, which failed to be obtained by classical approach. Indeed, $\mathrm{Lu}, \mathrm{Yb}$ and $\mathrm{Dy}$ complexes 3e-g were synthesized in $21-26 \%$ yields. ${ }^{[10]}$ This clearly evidences that elaborated method is general for the preparation of both bivalent and REE metal complexes. The yield decreasing from the compounds $3 \mathbf{e}-\mathbf{g}$ to complexes 3a-d could be explained by the lower stability of the REE complexes, because their metal ions are placed outside the phthalocyanine plane due to the larger ionic radii. Detection of side binuclear ligands during isolation of planar binuclear REE complexes appears to be a good evidence of this fact. The control experiment confirms the possibility of these compounds for demetallation under the reaction conditions.

The composition of the synthesized complexes 3a-d was confirmed by the presence of signals having characteristic isotopic pattern corresponding to molecular ion peaks in MS-MALDI-TOF. For the spectra of the REE complexes 3e-g registered using 2,5-dihydrobenzoic acid (DHB) as a matrix signals $\left[\mathrm{M}^{+}-2 \mathrm{OAc}+2 \mathrm{DHB}\right]$ were detected instead of molecular ions $\left(\left[\mathrm{M}^{+}\right]\right)$. This result additionally confirms earlier established fact ${ }^{[11]}$ of $\mathrm{Ln}-\mathrm{OAc}$ bond ionic nature. In the absence of matrix the corresponding spectra could not been obtained, which is likely to be related with low stability of molecular cation-radicals $\left(\left[\mathrm{M}^{+}\right]\right)$. Mass-spectrum of complex 3a is presented on Figure 1 as an example.

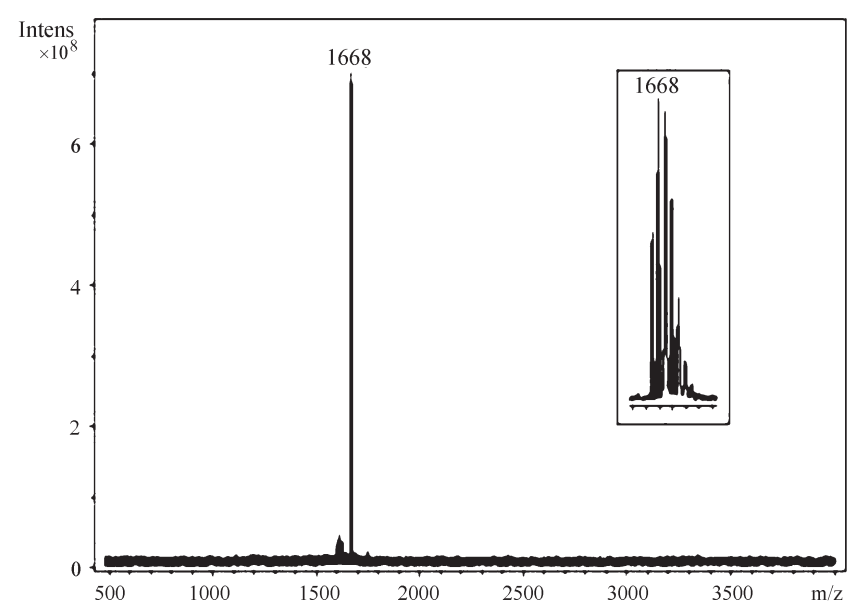

Figure 1. Mass spectrum (MALDI-TOF) of 3a (matrix - DHB). 
New Approach to Planar Binuclear Phthalocyanines

Table 1. UV-vis data for planar binuclear complexes 3a-g (THF).

\begin{tabular}{cccc}
\hline Compound & $Q$-band, $\lambda_{\max }, \mathrm{nm}(\lg \varepsilon)$ & $\mathrm{M}^{+}[\mathrm{m} / \mathrm{z}]^{[\mathrm{a}]}$ & Yield, $\%$ \\
\hline 3a & $363(4.69), 724(4.39), 848(4.89)$ & $1668^{[\mathrm{b}]}$ & 39 \\
3b & $359(4.85), 704(4.62), 847(4.92)$ & 1751 & 40 \\
3c & $362(4.76), 719(4.51), 836(4.99)$ & $1332^{[\mathrm{b}]}$ & 32 \\
3d & $358(4.64), 717(4.45), 835(5.01)$ & 1414 & 36 \\
3e & $358(4.85), 704(4.60), 834(4.86)$ & $1940^{[\mathrm{c}]}$ & 26 \\
3f & $356(4.83), 706(4.64), 837(4.81)$ & $1938^{[\mathrm{c}]}$ & 21 \\
3g & $353(4.85), 707(4.62), 837(4.82)$ & $1917^{[c]}$ & 23 \\
\hline
\end{tabular}

${ }^{[a]}$ By MALDI-TOF mass-spectrometry. The value corresponds to the most abundant isotopic peak of the molecular ion $\left[\mathrm{M}^{+}\right]$.

${ }^{[b]}$ Ion peak $\left[\mathrm{M}^{+}+\mathrm{H}\right]$.

${ }^{[c]}$ Ion peak $\left[\mathrm{M}^{+}-2 \mathrm{OAc}+2 \mathrm{DHB}\right]$.

For diamagnetic complexes 3a-e ${ }^{1} \mathrm{H}$ NMR spectra were recorded wherein signals of all protons were detected. Signals of the aromatic protons in spectrum of binuclear Lu phthalocyanine 3e were found to be shifted to a strong field on $2 \mathrm{ppm}$ unlike the complexes of bivalent elements 3a-d. Signals of the aliphatic protons have not been shifted virtually.

The planar binuclear complexes $\mathbf{3} \mathbf{a}-\mathbf{g}$ were characterized by UV-vis spectroscopy, their intensive absorption in the near IR region was found (Table 1) in comparison with mononuclear analogues (see Figure 2 for example).

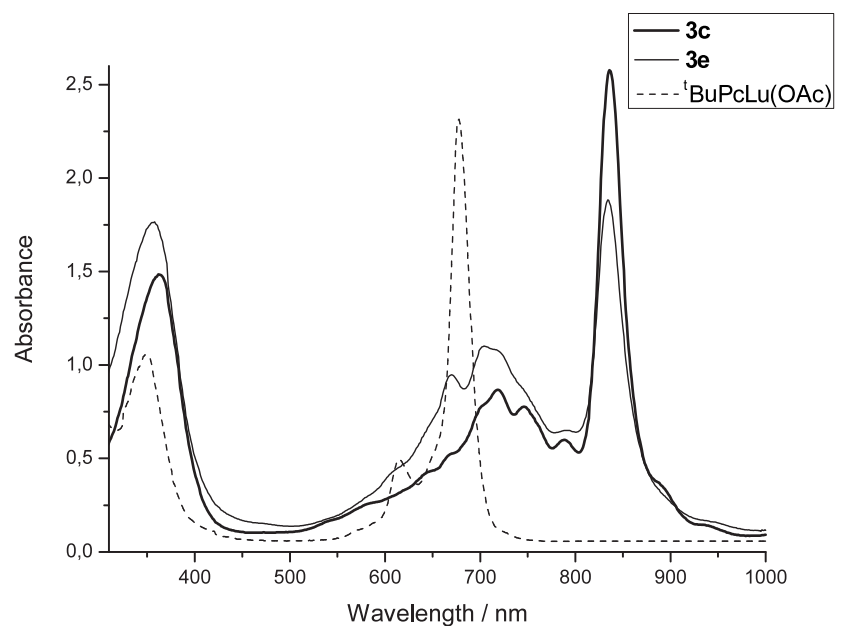

Figure 2. UV-vis spectra of complexes 3a (bold solid line), $\mathbf{3 e}$ (thin solid line) and ${ }^{\mathrm{t}} \mathrm{BuPcLuOAc}$ (dashed line) in THF.

As might be seen from the Table 1, the bathochromic shift of the $Q$-band is observed in the case of butyl-substituted complexes $\mathbf{3 a}, \mathbf{b}$ in comparison with tert-butyl planar binuclear phthalocyanines $\mathbf{3 c}$-g.

The nature of lanthanide ion does not affect the character of electronic spectra of $\mathbf{3 e - g}$ and the $Q$-band position as in the case of regular REE monophthalocyanines. ${ }^{[1]} \mathrm{UV}$-vis spectra of binuclear complexes $\mathbf{3} \mathbf{a}$ and $\mathbf{3} \mathbf{c}$ are presented on Figure 2 as an example.

\section{Conclusions}

We have developed a new approach to the synthesis of annulated planar binuclear phthalocyanines in high yields. The procedure elaborated allows to produce the divalent complexes as well as REE ones being assumed to be unique building blocks for preparing the supramolecular structures owing to the mobility of axial ligands.

Acknowledgements. This study was supported by the Russian Foundation for Basic Research (Grant no. 08-0300753) and the program of fundamental studies of Presidium of the Russian Academy of Sciences "Development of methods for synthesizing chemical compounds and creating new materials".

\section{References}

1. Zhang Y.J., Li Y., Liu Q., Jin J., Ding B., Song Y., Jiang L., Du X., Zhao Y., Li T.J. Synthetic Metals 2002, 128, 43-46.

2. Zhang Y.J., Li L.S., Jin J., Jiang S., Zhao Y., Li T.J. Langmuir 1999, 15, 2183-2187.

3. Makarov S., Litwinski C., Ermilov E.A., Suvorova O., Roder B., Woehrle D. Chem. Eur. J. 2006, 12, 1468-1474.

4. Tolbin A.Yu., Pushkarev V.E., Tomilova L.G., Zefirov N.S. Russ. Chem. Bull. 2006, 55, 1155-1159.

5. Leznoff C.C., Lam H., Marcuccio S.M., Nevin W.A., Janda P., Kobayashi N., Lever A.B.P. J. Chem. Soc., Chem. Commun. 1987, 699-701.

6. Cuellar E.A., Marks T.J. J. Inorg. Chem. 1981, 20, 3766-3770.

7. Hanack M., Metz J., Pawlowski G. Chem. Ber. 1982, 34, 28362853.

8. Kobayashi N. Coord. Chem. Rev. 2002, 127, 129-152.

9. Tolbin A.Yu., Ivanov A.V., Tomilova L.G., Zefirov N.S. J. Porphyrins Phthalocyanines 2003, 7, 162-166.

10. Tolbin A.Yu., Pushkarev V.E., Tomilova L.G., Zefirov N.S. Mendeleev Commun. 2008, 18, 94-95.

11. Subbotin N.B., Nemykin V.N., Voloshin Y.Z. Mendeleev Commun. 1993, 3, 3, 121-122. 